\title{
Effect of bearing preload on the dynamic characteristics of the spindle-bearing system
}

\author{
Gaofeng Hu ${ }^{1, a, *}$, Ye Chen ${ }^{1, b}$ Weiguo Gao ${ }^{1, c}$ and Dawei Zhang ${ }^{1, d}$ \\ ${ }^{1}$ Key Laboratory of Mechanism Theory and Equipment Design of Ministry of Education, Tianjin \\ University, Tianjin 300072, China \\ a gaofenghu@tju.edu.cn, ${ }^{\mathrm{b}}$ chenye@tju.edu.cn, ${ }^{\mathrm{c}}$ gaowg@tju.edu.cn, ${ }^{\mathrm{d}}$ medzhang@tju.edu.cn, \\ *corresponding author.
}

Keywords: Spindle-bearing system, Preload, Dynamic characteristic, Fixed position preload

Abstract: Angular contact ball bearings have been extensively utilized in machine tool spindles and the bearing preload plays a significant role on spindle stiffness, rotating precision, heat generation and service life span. With the development of high speed and high precision machining, especially for high speed grinding and milling, both heavy preload at low speed and light preload at high speed must been abled in series in a single machine tool spindle. In order to investigate the effect of the bearing preload on the performance of the spindle, we developed a spindle test rig. In this paper. The effect of bearing preload on the dynamic characteristics of the spindle-bearing system was investigated. The working principle of fixed position preloading method of the spindlebearing system are introduced. For the spindle that utilizing fixed position preloading method, the theory of assembly dimensional chain was applied to analyze the preloading state of the spindle-bearing system in static conditions. The equivalent parametric identification model was established. The finite element dynamic analysis model of the spindle assembly was developed by taking the advantage of the spring-damper elements to simulate the bearing supports. Finite element analysis (FEA) was conducted to evaluate the effect of the preload on the dynamic characteristics of the spindle-bearing system. This paper not only provides guidance on how to correctly assembling high speed and high precision spindle, but also lay a foundation for the investigation of thermal-mechanicaldynamic characteristic of high speed spindle-bearing system.

\section{Introduction}

The spindle is one of the most important components that limit the overall dynamic stiffness of the machine tool. The bearing preload has a great influence on the dynamic characteristic of spindle systems, With the development of ultra high speed machining, especially for high speed milling, the accurate preload of the spindle-bearing system should be ensured in the spindle assembly process. Various preload mechanism was fabricated in the past, however, the application of active preload control in practice is uncommon. In order to optimize the dynamic characteristics, thermal 
characteristics, rotational accuracy, and fatigue life of the spindle-bearing system in a wide range of spindle rotational speeds, correctly assembling and the preloading principle of the spindle is indispensable. In recent year spindle experts all over the world have done a lot of research on the bearing preload technology ${ }^{[1]}$. They mainly focused on the design of the bearing preload mechanism and the calculation of the optimum preload ${ }^{[2-4]}$. However, little investigation has been conducted on the assembling of the spindle, which determines the initial preload of the spindle, and the effect of bearing preload after spindle assembly on the dynamic characteristics of the spindlebearing system. In this paper we define the preload after spindle assembly as the initial bearing preload.

Literature review shows that the exist bearing preloading method can be divided into fixed position preload and constant pressure preload ${ }^{[5]}$. Cao ${ }^{[6]}$ investigated the effect of the preload on the dynamics of high speed spindles with respect to different preload mechanisms and conclude that at high speeds and under cutting loads the rigid preload mechanism is more efficient in maintaining the dynamic stiffness of spindles than constant preload. Jui-Pin Hung ${ }^{[7]}$ presents an investigation on the variation of dynamic characteristics of a spindle under the influence of the bearing preload. Jiang shuyun ${ }^{[8]}$ developed a method to analyze the variable preload with rotation speed for a high speed machining spindle utilizing hydraulic actuator. $\mathrm{Li}$ xiaohu ${ }^{[9]}$ investigation of non-uniform preload on the static and rotational performances for spindle bearing system. J. Jedrzejewski ${ }^{[10]}$ presents modelling of moving sleeve and spindle tip displacements in spindle bearing systems equipped with angular contact ball bearings. Yuzhong Cao and Y. Altintas ${ }^{[11]}$ developed a general, integrated model of the spindle bearing and machine tool system, consisting of a rotating shaft, tool holder, angular contact ball bearings, housing, and the machine tool mounting. Aydin Gunduz and Jason T. Dreyer ${ }^{[12]}$ investigates the role of bearing preloads on the modal characteristics of a shaftbearing assembly with a double row angular contact ball bearing.

As mentioned above, the researchers do a lot of work on the bearing preload technology. However, none of them analysed the preload of spindle-bearing system from the viewpoint of spindle assembling and the effect of bearing preload on the dynamic characteristics of the spindlebearing system. The main objective of this paper is to investigate the effect of bearing preload on the dynamic characteristics of the spindle-bearing system The working principle of fixed position preloading method of the spindle-bearing system are introduced. For the spindle that utilizing fixed position preloading method, the theory of assembly dimensional chain is applied to analyze the preloading state of the spindle-bearing system in static conditions. The axial stiffness and radial stiffness of the bearing under different preload is calculated. Finite element analysis (FEA) was conducted to evaluate the effect of the preload on the dynamic characteristics of the spindle test rig. This paper not only provides guidance on how to correctly assembling high speed and high precision spindle, but also lay a foundation for the investigation of thermal-mechanical-dynamic characteristic of high speed spindle-bearing system.

\section{The principle of fixed position preloading method}

A position preload is achieved by fixing two axially opposed bearings in a position that remains unchanged while in operation. In engineering application, when we design a high speed spindle, first we have to select the preload type of bearing combination. According to the measured axial clearances, five types of bearings with different preload (EL L M CA CP) are provided by NSK, Inc. However, in engineering application, according to the selected bearing combination, in order to change preload, we could adjust the difference of the measured axial clearance, by a spacer. That is to say when increasing the preload, inner spacer should be shorter, and outer spacer should be shorter when decreasing preload, as shown in figure 1. From the viewpoint of spindle assembling, 
changing the thickness of the spacer is the fitting way in the assembly process and method. Although the assembling process is complex for fitting way, it has a high assembling accuracy. In the assembling process of the precision spindle, the required axial clearance of the bearing is exactly ensured. To some extent the close-chain A6, A7 represents the axial clearance of the bearing, which determines the tolerance of the other composition loop dimension, take A0, A1 for example. It should be specially explained that, Thermal-elastic effect induced deformation of the inner and outer spacer, will greatly influenced the preload of the bearing.
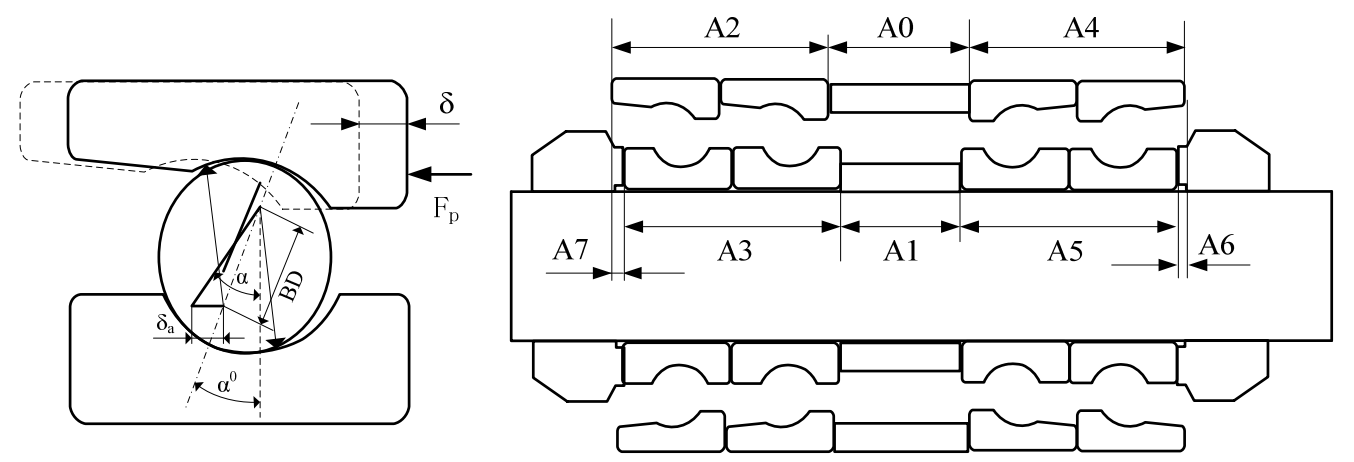

Figure 1 The assembly dimensional chain of the double back to back bearing arrangement

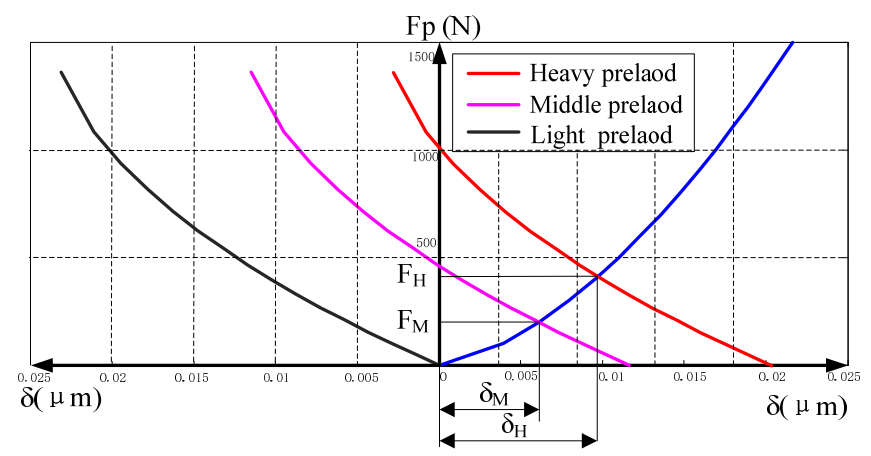

Figure 2 The preloaded axial displacement of DB arrangement.

When the inner rings of the bearings are fixed axially, the preload $\mathrm{F}_{\mathrm{P}}$ is imposed on each bearing. The relationship between axial load FP and displacement $\delta$ is shown in Fig. 2. With increase of the preload, the axial clearance of the bearing will decrease. $\delta \mathrm{M}$ and FM represents middle preload axial clearance and middle preload respectively. In the same way, $\delta \mathrm{H}$ and $\mathrm{FH}$ represents heavy preload axial clearance and heavy preload respectively. When the cutting force imposed on the spindle, the load of on the bearing will increase while the load of the opposed bearing will decrease.

\section{Simulation analyses of the spindlle-bearing system}

The simulation model of the spindle-bearing system was made by establishing the equivalent parametric identification model. The simplified model of the spindle-bearing system is shown in Figure 3. The stiffness of the bearing simplified axial stiffness and radial stiffness, denoted by $\mathrm{K}_{\text {eqa }}$ and $\mathrm{K}_{\text {eqr }}$ respectively, the damping of the bearing simplified axial damping and radial damping, denoted by $\mathrm{C}_{\text {eqa }}$ and $\mathrm{C}_{\text {eqr }}$ respectively. Since the bearing preload and bearing parameter are the significant factors for the spindle-bearing system, the bearing parameter and the recommended preload values are tabulated in Table 1 and 2. The proposed preload value represents that on one single ball bearing only. As the spindle system is installed with a bearing configuration form of double back to back (DBB), the recommended preload value is twice as the preload for the single 
bearing according to the NSK bearing handbook. Ansys software was use to simulated the spindlebearing system. The finite element dynamic analysis model of the spindle assembly was developed by taking the advantage of the spring-damper elements to simulate the bearing supports.

Table 1 Bearing type of the spindle-bearing system.

\begin{tabular}{|c|c|c|c|c|}
\hline Bearing type & Inner diameter & Outer Diameter & width & Congtact angle \\
\hline NSK 65BNR10H & $65 \mathrm{~mm}$ & $100 \mathrm{~mm}$ & $18 \mathrm{~mm}$ & $18^{\circ}$ \\
\hline
\end{tabular}

Table 2 Proposed preload value of the bearing.

\begin{tabular}{|c|c|c|c|}
\hline Bearing type & Extreme light preload & Light preload & Middle preload \\
\hline NSK 65BNR10H & $50 \mathrm{~N}$ & $140 \mathrm{~N}$ & $413 \mathrm{~N}$ \\
\hline
\end{tabular}
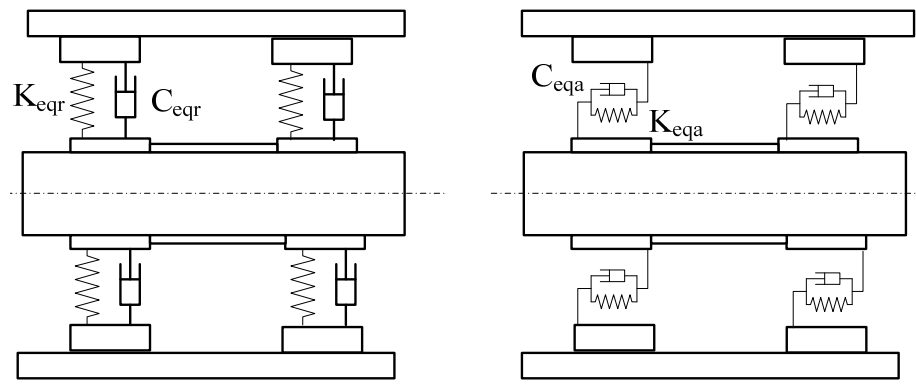

Figure 3 The equivalent parametric identification model.

The axial and radial stiffness of the spindle-bearing system under different preload are shown in figure 6 . When the preload of $100 \mathrm{~N}, 280 \mathrm{~N}$ and $826 \mathrm{~N}$ were exerted on the spindle-bearing system successively, the radial stiffness is $540 \mathrm{~N} / \mu \mathrm{m}, 783 \mathrm{~N} / \mu \mathrm{m}, 1170 \mathrm{~N} / \mu \mathrm{m}$ and the axial stiffness is $120 \mathrm{~N} / \mu \mathrm{m}, 174 \mathrm{~N} / \mu \mathrm{m}, 260 \mathrm{~N} / \mu \mathrm{m}$ respectively. We can conclude that as the preload is improved, the axial and radial stiffness of the spindle bearing system will increase.

Besides, the modal analysis is performed by FEA to investigate the dynamic performance of the spindle-bearing system, as illustrated in Fig. 6. The corresponding natural frequencies for the first order mode shapes are $563 \mathrm{~Hz}, 575 \mathrm{~Hz}$ and $607 \mathrm{~Hz}$ under extreme light preload, light preload and middle preload respectively. We can conclude that as the preload is improved, The natural frequencies for the first order mode shapes of the spindle bearing system will increase.

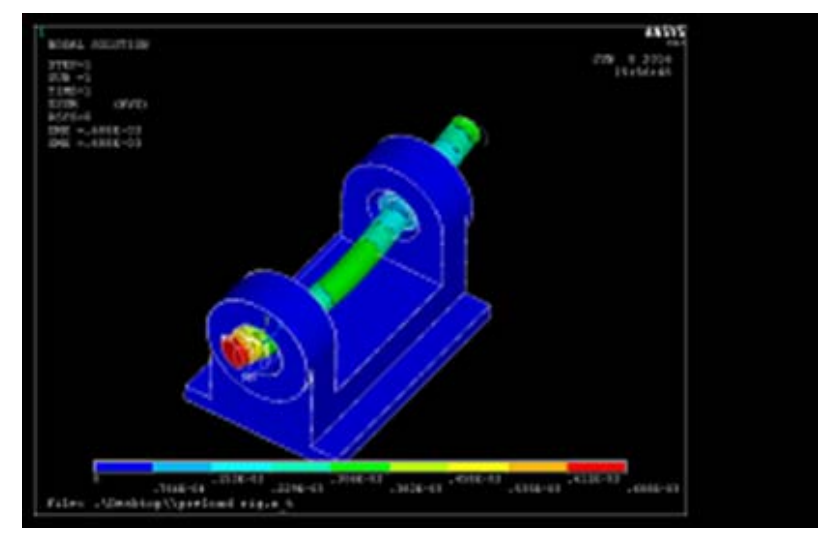

Figure 4 The radial stiffness of spindle-bearing system under the preload $826 \mathrm{~N}$. 


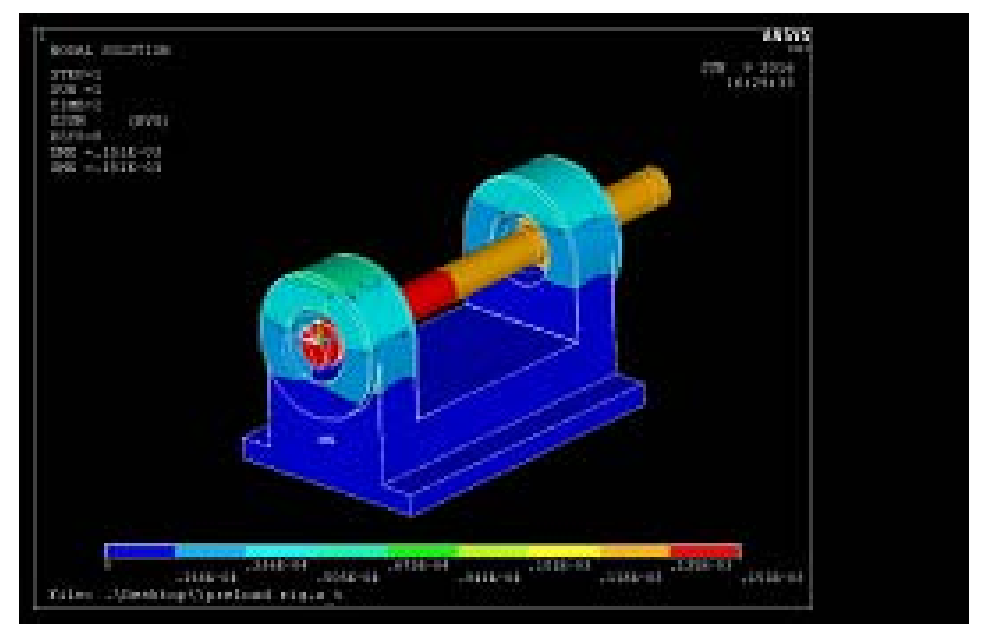

Figure 5 The axial stiffness of spindle-bearing system under the preload $826 \mathrm{~N}$.

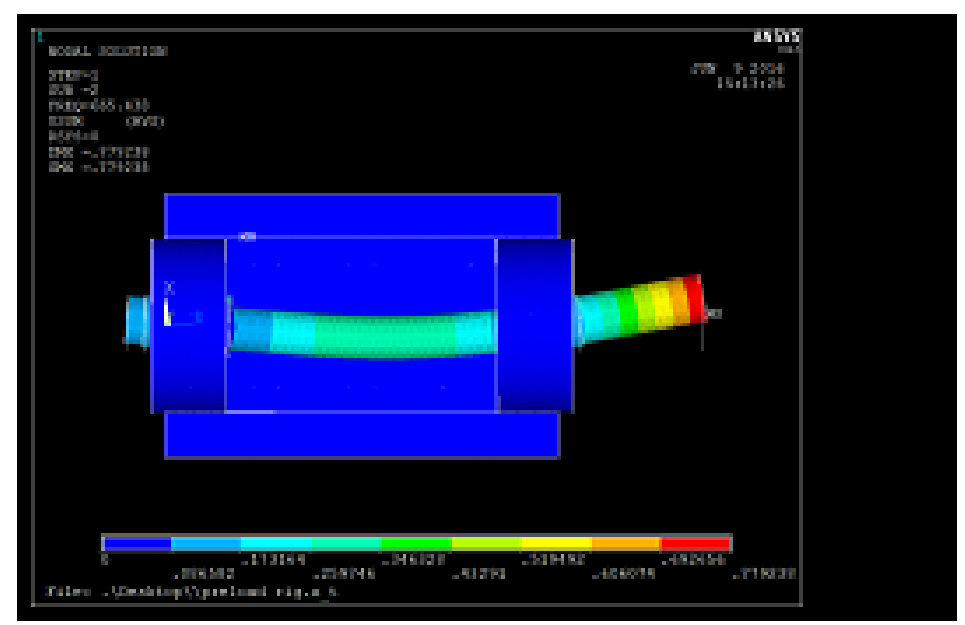

Figure 6 The first order mode shapes under the preload $826 \mathrm{~N}$.

\section{Conclusions}

This study presents the working principle of fixed position preloading method of the spindlebearing system. The theory of assembly dimensional chain is applied to analyze the preloading state of the spindle-bearing system in static conditions. The simulation model of the spindle-bearing system was made by establishing the equivalent parametric identification model. The finite element dynamic analysis model of the spindle assembly was developed by taking the advantage of the spring-damper elements to simulate the bearing supports. Finite element analysis (FEA) was conducted to evaluate the effect of the preload on the dynamic characteristics of the spindle-bearing system. This paper not only provides guidance on how to correctly assembling high speed and high precision spindle, but also lay a foundation for the investigation of thermal-mechanical-dynamic characteristic of high speed spindle-bearing system.

\section{Acknowledgements}

This work was supported by the National Science and Technology Major Project of China under Grant No. 2016ZX04004-002 and No.2015ZX04005-001. 


\section{References}

[1] H.R. Cao, X. W. Zhang, X.F. Chen, The concept and progress of intelligent spindles: A review, Int. J. Mach. Tools Manuf. 112 (2017) 21-52.

[2] Y.K. Hwang, C.M. Lee, Development of automatic variable preload device for spindle bearing by using centrifugal force, Int. J. Mach. Tools Manuf. 49 (2009) 781-787.

[3] Q.D. Yang, K.S. Wang, L.X. Meng, H.L. Zhao, Design method of automatic adjustment of bearing preload based on thermal characteristic of materials, Chinese Journal of Mechanical Engineering. 44(2008) 183-187.

[4] Kitamura Koichiro, Katsuji Taniguchi. Preload control apparatus for bearings with shape memory alloy springs, United States Patent 5094551.1992 Mar. 10.

[5] NSK. Catalogue-Super precision bearings. 138-139, 2011.

[6] Hongrui Cao, Tomas Holkup, Yusuf AltintasInt, A comparative study on the dynamics of high speed spindles with respect to different preload mechanisms, J Adv Manuf Technol (2011) 57:871-883.

[7] JuiPin Hung, Yuan-Lung Lai, Tzuo, Liang Luo, Analysis of the machining stability of a milling machine considering the effect of machine frame structure and spindle bearings: experimental and finite element approaches, Int J Adv Manuf Technol (2013) 68:2393-2405.

[8] S.Y. Jiang, H.B. Mao, Investigation of variable optimum preload for a machine tool spindle, Int. J. Mach. Tools Manuf. 50 (2010) 19-28.

[9] X. H. Li, H.F. Li, Y.F. Zhang, J. Hong, Investigation of non-uniform preload on the static and rotational performances for spindle bearing system, Int. J. Mach. Tools Manuf. 106 (2016) 11-21.

[10] J. Jedrzejewski, W. Kwasny, Modelling of angular contact ball bearings and axial displacements for highspeed spindles, CIRP Annals - Manufacturing Technology. 59 (2010) 377-382.

[11] Yuzhong Cao, Y. Altintas. Modeling of spindle-bearing and machine tool systems for virtual simulation of milling operations, Int. J. Mach. Tools Manuf. 47 (2007) 1342-1350.

[12] Aydin Gunduz, Rajendra Singh, Effect of bearing preloads on the modal characteristics of a shaft-bearing assembly: Experiments on double row angular contact ball bearings, Mechanical Systems and Signal Processing 31 (2012) 176-195. 